\title{
ACOLHIMENTO AOS PROFISSIONAIS DE ENFERMAGEM EM SITUAÇÃO DE PANDEMIA
}

Margrid Beuter'

ORCID: 0000-0002-3179-9842

Marinês Tambara Leite"

ORCID: 0000-0003-3280-337X

Caren da Silva Jacobi"I ORCID: 0000-0002-8917-6699

Rosimere Ferreira Santanalv

ORCID: 0000-0002-4593-3715

Carolina Backes ${ }^{v}$

ORCID: 0000-0002-2504-9105

Rafael Beuter Nishijimavı

ORCID: 0000-0002-5402-6121

I, III, U Universidade Federal de Santa Maria. Santa Maria, Rio Grande do Sul, Brasil.

"Universidade Federal de Santa Maria. Palmeira das Missões, Rio Grande do Sul, Brasil.

"Universidade Federal Fluminense. Niterói, Rio de Janeiro, Brasil.

V' Universidade Franciscana. Santa Maria, Rio Grande do Sul, Brasil.

Autor Correspondente: Margrid Beuter E-mail:margridbeuter@gmail.com

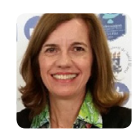

Como citar:

Beuter M, Leite MT, Jacobi CS, Santana RF, Backes

C, Nishijima RB. Acolhimento aos profissionais de enfermagem em situação de pandemia.

In: Santana RF. Enfermagem gerontologica no cuidado do idoso em tempos da COVID 19. 2.ed.rev. Brasilia, DF: Editora ABEn; 2020. p.66-70.

(Serie Enfermagem e Pandemias, 1). https://doi.org/10.51234/aben.20.e01.c11

\section{INTRODUÇÃO}

A COVID-19 é uma doença causada pelo coronavírus SARS-CoV-2, descoberto em 2019 na China. A doença apresenta um quadro clínico variável de infecções assintomáticas a quadros respiratórios graves. Sua transmissão ocorre pelo contato com gotículas de saliva, espirro, tosse, secreções respiratórias ou com superfícies contaminadas por pessoas infectadas ${ }^{(1)}$. A afecção de um grande número de pessoas por diversos países do mundo levou a Organização Mundial da Saúde a declarar a situação de pandemia por COVID-19. Em 18 abril de 2020, o número de casos confirmados no mundo era de 2.276 .547 com 156.141 óbitos ${ }^{(2)}$.

O quantitativo de casos no Brasil, em 20 de abril de 2020, era de 40.581 e 2.575 óbitos pela COVID-19, sendo $72 \%$ das mortes na população com mais de 60 anos ${ }^{(1-2)}$. Porém, vale ressaltar, que há subnotificação dessa incidência, por causas diversas, entre elas: impossibilidade de realização de testes em todos os suspeitos; tempo de análise dos testes, devido à sobrecarga dos laboratórios responsáveis e de alguns hospitais; parcela da população vai a óbito sem procurar o serviço de saúde, podendo ser testada somente posteriormente, por meio da vigilância em saúde; em muitos casos a doença é assintomática; e, também, há situações de erros de diagnóstico, quando a avaliação do agravo é atribuída a outra morbidade.

Desse modo, estima-se que o número real de afetados pela COVID-19 seja muito maior do que o relevado. Dentre as pessoas acometidas estão os profissionais de saúde, em especial, os que atuam diretamente em contato com os pacientes, como os integrantes da equipe de enfermagem. No início do mês de abril de 2020, no Brasil, havia 30 óbitos de profissionais de enfermagem causadas pela doença e 4.604 estavam afastados de seu trabalho pela contaminação por COVID-19 (3).

A magnitude dessa ocorrência ameaça o sistema de saúde e os profissionais que nele atuam, no sentido de 
evitar colapsos no atendimento as diversas demandas que emergem, tanto no plano de atenção à população, como de recursos humanos. Nesse cenário, os profissionais de enfermagem foram convocados a atender tais necessidades com seus conhecimentos e habilidades técnicas, porém com domínio insuficiente sobre o manejo de como lidar com pacientes acometidos pelo vírus SARS CoV-2, já que a pandemia evolui de forma muito rápida.

Assim, esses profissionais passaram a enfrentar dilemas relacionados à impossibilidade de contato com familiares, acompanhamento de mortes frequentes, hostilidade de integrantes da sociedade, que os consideram vetores de transmissão, carência de equipamentos de proteção individual (EPI), culminando com longos períodos de trabalho ininterrupto. Também, precisam lidar com o medo de se contaminar e morrer, sobrecarga de trabalho em função do aumento de atividades e pelo fato de colegas estarem adoecendo, como tem sido divulgado na mídia diariamente, e com o sofrimento de familiares dos pacientes que precisam manter-se distantes, sem poder acompanhar o processo de morrer de seu ente querido.

Logo, enfrentar a realidade provocada pela COVID-19, afeta os trabalhadores da saúde em situações vivenciadas direta ou indiretamente. Eles podem manifestar seu sofrimento psíquico como: ansiedade; depressão; prejuízo na qualidade do sono; aumento do uso de drogas lícitas e ilícitas; sintomas psicossomáticos. Ainda há o medo de se infectarem ou transmitirem o vírus aos familiares intensificando o sofrimento psíquico ${ }^{(4)}$. A qualidade da saúde mental desses profissionais está intimamente conectada a capacidade de desempenho de seu trabalho - trabalhar enquanto abriga grande sofrimento psíquico prejudica ou impede a execução do trabalho do profissional.

Pesquisa com profissionais de saúde que atuavam na atenção primária à saúde identificou que estes trabaIhadores, em sua prática cotidiana, vivenciavam situações complexas relacionadas às condições de trabalho inadequadas, desde a infraestrutura deficitária, falta de materiais e excesso de demandas assistenciais e administrativas, gerando sobrecargas, até conflitos interpessoais entre os integrantes da equipe no espaço de trabalho. Essas situações desencadeavam nos profissionais sentimento de impotência, inutilidade, frustração e desestímulo, com impactos negativos nas atividades laborais e, consequentemente, com comprometimento da sua saúde mental(5). Entende-se que em tempos de pandemia, como a do coronavírus, as condições de trabalho sejam piores e os resultados sobre a saúde física e mental dos profissionais se exacerbam.

Ainda, considera-se que, na sociedade atual, a ansiedade, sintomas depressivos e o estresse são condições que podem comprometer a saúde mental dos profissionais de saúde e em tempos de pandemia novos desafios são enfrentados, pois as exigências são maiores e, provavelmente, tais manifestações estão presentes em grande parte dos profissionais. Neste sentido, estudo mostrou que depressão, ideação e tentativas de suicídio, uso abusivo de álcool e outras drogas, estresse, ansiedade, cansaço e esgotamento profissional são circunstâncias presentes e comuns no cotidiano da prática de profissionais de saúde ${ }^{(6)}$. Ainda, os transtornos de ansiedade se constituem em fator importante, que leva profissionais ao afastamento do trabalho por interferir significativamente na vida do trabalhador e daqueles que convivem com ele, além de prejudicar suas atividades e suas relações sociais ${ }^{(7)}$.

Vale destacar que o cuidado de enfermagem abrange atividades funcionais de manutenção, promoção, restauração da saúde e assistência num contexto de humanização, de liberdade e de autonomia, atuando como suporte para condições de vida saudável ${ }^{(8)}$. Entretanto, a necessidade de usar diversos EPIs durante o cuidado de enfermagem à pessoa com COVID-19 limita drasticamente a comunicação não verbal e desfigura o vínculo por essa via. Assim, percebe-se que algumas dimensões não são passíveis de serem contempladas no cenário de pandemia por coronavírus, provocando ainda mais sofrimento e dificultando o estabelecimento da empatia com o paciente. Tais fatores, ao limitar o vínculo empático com o paciente, contribuem também para a deterioração da saúde mental do trabalhador de enfermagem.

Diante dessa situação, estratégias para manter a saúde mental dos profissionais precisam ser conjecturadas, uma delas é o acolhimento. Preconizado no Sistema Único de Saúde (SUS) pela Política Nacional de Humanização (PNH) como uma diretriz, de uso fundamental no primeiro contato do paciente. $O$ acolhimento 
incorpora aspectos éticos e políticos, sendo um modo de produzir saúde e constituir uma ferramenta na construção de vínculo que responde às necessidades daqueles que procuram serviços de saúde ${ }^{(9)}$. Mas seu uso não necessita permanecer restrito entre profissional para o paciente que procura atendimento.

Considerando as possibilidades do acolhimento já reconhecidas e seu emprego disseminado pela Enfermagem nos diversos cenários de atuação, pode-se supor que tal ferramenta está subutilizada em seu uso entre os profissionais da equipe - restringindo a aplicação aos usuários. Isso se torna notável durante a conjuntura provocada pela pandemia, com o sofrimento psíquico dos profissionais de enfermagem, em que há necessidade de alento durante situações atrozes ou exaustivas. Em tais situações, o acolhimento é uma ferramenta capaz de dirimir o sofrimento e suportar elas até o fim de eventos traumáticos - mortes de pacientes ou contaminações confirmadas - e para buscar outras formas de tratar ou lidar com o sofrimento psíquico crônico.

Frente a essas ponderações e a necessidade da proteção à saúde mental dos profissionais de enfermagem, torna-se mister refletir sobre as possibilidades do acolhimento na equipe de enfermagem durante $o$ enfrentamento da situação gerada pela pandemia por COVID-19.

\section{POSSIBILIDADES NO ACOLHIMENTO À EQUIPE DE ENFERMAGEM ATUANTE NO ENFRENTAMENTO DA PANDEMIA POR COVID-19}

A pandemia da COVID-19 atinge particularmente as populações com comorbidades - em especial, com idade avançada - e também aqueles que cuidam deles. Os profissionais trabalham com essas pessoas afetadas pela enfermidade e além do risco de ingressar como doente ou tornar-se vetor, também precisam lidar com o sofrimento dos pacientes, dos familiares que telefonam, e com o seu próprio.

O risco de contaminação por si só, já é um fator de estresse atroz para o profissional, e precisar enfrentá-lo todo dia irá cronificar se nada for feito. Para melhorar a saúde mental do profissional de saúde, há diversas medidas: como terapias, para grandes sofrimentos; e medidas recreativas ou descanso, para lidar com a dor e fadiga diários. Mas durante o trabalho, ou logo após ele, pode haver necessidade inadiável, um sofrimento tão agudo, que necessite ser atendido no momento ou em curto intervalo. Nessas situações, pode-se recorrer ao acolhimento.

O cuidado da enfermagem não pode se furtar de enfrentar situações de sofrimento e morte, principalmente de idosos em hospitais e Instituição de Longa Permanência para Idosos (ILPI), tal é inexorável a ele - uma vez que lhe é competência e objetivo prestar o cuidado a quem necessita. Durante a pandemia, os idosos constituem a população com maior taxa de mortalidade pela COVID-19, então, locais como os hospitais e as ILPI são os que requisitarão maiores cuidados pelos riscos inerentes à estrutura. Profissionais que trabalham nesses ambientes estarão expostos a situações extremas e necessitarão de apoio, alívio do sofrimento decorrente dos estados críticos dos idosos.

Para fornecer o acolhimento são necessários alguns requisitos: disposição, "estabilidade" emocional e vinculação com a pessoa que se busca acolher. Disposição no sentido de tempo para permanecer com a pessoa acolhida, variável com a situação, e ficar presente. É necessário dispor de atenção a ela - a experiência e as sensações que a pessoa lhe endereça. Frente ao que é vivenciado e transmitido para o profissional que acolhe, esse conteúdo precisa ser suportado para possibilitar o acolhimento. O profissional precisa avaliar se está em condições de prestar o acolhimento levando em conta seu estado emocional e o que está sendo experienciado e relatado pela pessoa acolhida. O vínculo entre quem acolhe e o acolhido vai definir as possibilidades do acolhimento. Com tal sofrimento, é insuficiente enunciar somente dados científicos - resultados de exames, procedimentos das técnicas - e urge atendê-las em sua agonia.

O acolhimento não se restringe ao primeiro contato do usuário com o serviço, não tem hora certa para acontecer e não pode ser confundido com a prática de triagem. É uma ferramenta de cuidado e criação de vínculo, pautada na escuta qualificada e humanizada dos sujeitos. Acolhe-se também, por exemplo, em momentos de agravamento dos problemas de saúde, garantindo a manutenção ou fortalecimento do vínculo, 
que consiste num alicerce constitutivo dos processos de produção de saúde mental. Desse modo, a escuta é uma ação terapêutica e, como primeiro contato, o acolhimento inicial é um momento estratégico para o estabelecimento de vínculo com o outro(9).

Acolher é, portanto, comprometer-se com o outro. Ainda, acolhe-se não apenas os usuários do sistema de saúde, mas também os profissionais do serviço e de outros serviços da rede, ao assumir uma postura de apoio e de compartilhamento de saberes, dúvidas, inquietações e experiências. Como está posto na PNH, colocar em prática o acolhimento num espaço de saúde provoca "mudanças estruturais na forma de gestão do serviço de saúde, ampliando os espaços democráticos de discussão/decisão, de escuta, trocas e decisões

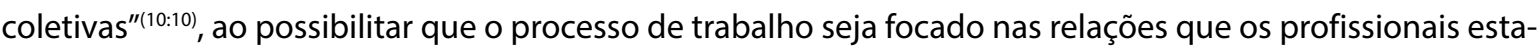
belecem entre si, com os usuários, com a comunidade e com outros serviços.

Vale lembrar que o cuidar e ser cuidado envolve interação de pessoa com pessoa. Uma relação em que seres humanos juntos constroem vínculos profissionais e, de algum modo, afetivos que tornam pessoas e situações preciosas, investidas de valor. Isto se evidencia não só em relação à díade trabalhador da saúde e usuário, mas, também, entre os integrantes da equipe profissional. Nesse campo de relação há contínua pressão sob o profissional de que ele não pode errar, pois está lidando com um ser humano, afinal seu objeto de trabalho são pessoas atingidas em sua integridade física, psíquica e social, alguém que expressa sofrimento e mobiliza sentimentos no profissional que o cuida, o que exige resultados muitas vezes superiores à possibilidade humana de alcançá-los ${ }^{(9-10)}$.

Assim, o trabalhador da enfermagem encontra-se continuamente envolvido na responsabilidade de cuidar o outro. No entanto, esses profissionais também são sujeitos de sofrimentos e medos e, como tal, necessitam de cuidado. Precisam de alguém que lhes invista um olhar de atenção, de continência das angústias e ansiedades despertadas em cada caso, no contato com a dor e o sofrimento dos usuários que atende ${ }^{(9-10)}$. Isto porque há situações em que o profissional realiza todas as medidas cabíveis, mas não conseguiu revertê-las. Nelas, o profissional encontra-se, talvez, em seu ponto mais crítico de sofrimento psíquico. Aqui, a equipe pode acolher seu integrante e aliviar seu sofrimento psíquico a um ponto suportável para ele, mesmo que durante um curto período, e encaminhar aos auxilio de profissionais da saúde mental psicólogos e psiquiatras sempre que necessário, acolhendo o sofrimento psíquico com seriedade que merece.

Considerando as dificuldades, requisitos e benefícios do acolhimento, ressalta-se a necessidade de preparo da equipe de enfermagem e multiprofissional em acolher os trabalhadores. A equipe deve reconhecer as limitações de seus integrantes e suas capacidades durante a pandemia. $\mathrm{O}$ acolhimento é uma das formas de apoio à saúde mental da enfermagem para a equipe e não, necessariamente, apenas para os usuários do SUS.

\section{CONSIDERAÇÕES FINAIS}

O acolhimento é uma estratégia importante para a saúde dos profissionais de enfermagem que atuam em situação de pandemia. Entende-se que acolher o colega que também enfrenta a mesma e árdua realidade pode ser um desafio, pois os vínculos construídos entre a equipe são diversos e específicos para cada profissional - enquanto a vinculação é fundamental ao acolhimento. Tais vínculos irão definir as possibilidades de acolher em determinadas situações e entre diferentes colegas.

Acolher reduz o sofrimento psíquico de profissionais atuantes no combate a COVID-19. Por isso, oferecer acolhimento é uma forma de ajudar o colega da equipe de enfermagem a enfrentar o medo e a insegurança que permeiam uma situação de pandemia e propicia tantas situações de sofrimento e ajuda a decidir pelo melhor encaminhamento do sofrimento do profissional.

\section{AGRADECIMENTO}

Ao Departamento Científico de Enfermagem Gerontológica da ABEn Nacional. 


\section{REFERÊNCIAS}

1. Ministério da Saúde. Coronavírus COVID-19 [Internet]. Brasília: Ministério da Saúde; 2020 [Citado 2020 Abr 20]. Disponível em: https://coronavirus.saude.gov.br/

2. Ministério da Saúde. Boletim epidemiológico coronavírus no 12 [Internet]. Brasília: Ministério da Saúde; 2020 [Citado 2020 Abr 20]. Disponível em: https://portalarquivos.saude.gov.br/images/pdf/2020/April/19/BE12-Boletim-do-COE.pdf

3. Conselho Federal de Enfermagem. Brasil tem 30 mortes a enfermagem por COVID-19 e 4.000 profissionais afastados [Internet]. [Citado 2020 Abr 20]. Disponível em: http://www.cofen.gov.br/brasil-tem-30-mortes-na-enfermagem-por-covid19-e-4-mil-profissionais-afastados_79198.html

4. Ministério da Saúde (BR). Fundação Oswaldo Cruz. Saúde Mental e Atenção Psicossocial na Pandemia COVID-10. Recomendações para Gestores. Ministério da Saúde: Brasília, 2020. Disponível em: https://www.fiocruzbrasilia.fiocruz. br/wp-content/uploads/2020/04/Sa\%C3\%BAde-Mental-e-Aten\%C3\%A7\%C3\%A3o-Psicossocial-na-Pandemia-Covid-19recomenda\%C3\%A7\%C3\%B5es-para-gestores.pdf

5. Costa IP, Pimenta CJL, Brito MJM. Adversities experienced by professionals in the Primary Healh Care: implications for the meanings of the work. Esc Anna Nery. 2019; 23(3): e20180373. doi: 10.1590/2177-9465-ean-2018-0373.

6. Souza HA, Bernardo MH. Prevenção de adoecimento mental relacionado ao trabalho: a práxis de profissionais do Sistema Único de Saúde comprometidos com a saúde do trabalhador. Rev bras saúde ocup. 2019; (44): e26. doi: 10.1590/2317-6369000001918.

7. Ribeiro HKP, Santos JDM, Silva MG, Meideiro FDA, Fernandes MA. Transtornos de ansiedade como causa de afastamentos laborais. Rev bras saúde ocup. 2019; (44): e1. doi: 10.1590/2317-6369000021417.

8. Souza ML, Sartor VVB, Padilha MICS, Prado ML. O Cuidado em Enfermagem: uma aproximação teórica. Texto contexto enferm. 2005; 1(2): 266-70. doi: 10.1590/S0104-07072005000200015.

9. Ministério da Saúde. Secretaria de Atenção à Saúde. Política Nacional de Humanização. Formação e intervenção. Série B. Textos Básicos de Saúde. Cadernos HumanizaSUS. Brasília: Ministério da Saúde; 2010.

10. Ministério da Saúde. Secretaria de Atenção à Saúde. Núcleo Técnico da Política Nacional de Humanização. HumanizaSUS: acolhimento com avaliação e classificação de risco: um paradigma ético-estético no fazer em saúde. Brasília: Ministério da Saúde; 2004. P.10 